\title{
3 Research Square

\section{A cross-sectional study of demonstrating expertise and job satisfaction in pharmacists and dietitians working in community pharmacies in Japan}

Masaki Shoji ( $\sim$ masaki.shoji@ompu.ac.jp )

Osaka Medical and Pharmaceutical University

Naoki Sakane

National Hospital Organization Kyoto Medical Center

Naoki lto

Ito-Yaku Ltd

Keiji Sunayama

Ito-Yaku Ltd

Mitsuko Onda

Osaka Medical and Pharmaceutical University

\section{Research Article}

Keywords: MHLW, Pharmacy Vision for Patients, Expertise, pharmacists and dietitians, standard deviation, demonstrating expertise

Posted Date: November 12th, 2021

DOI: https://doi.org/10.21203/rs.3.rs-1042844/v1

License: (c) (i) This work is licensed under a Creative Commons Attribution 4.0 International License.

Read Full License

Version of Record: A version of this preprint was published at Pharmacy Practice on March 26th, 2022.

See the published version at https://doi.org/10.18549/PharmPract.2022.1.2605. 


\section{Abstract \\ Background}

In Japan, there has been a private-sector initiative to register dietitians in pharmacies. There is not yet an adequate amount of data on the attitudes of dietitians in pharmacies regarding their work.

\section{Objectives}

To assess the attitudes of pharmacists and dietitians working in community pharmacies in Japan about their work, and particularly about demonstrating expertise and overall job satisfaction.

\section{Methods}

We administered a web-based questionnaire to pharmacists and dietitians working in pharmacy branches with registered dietitians at two pharmacy chains that agreed to cooperate. We used our own 7-item questionnaire and compared the scores for each item between pharmacists and dietitians.

\section{Results}

A total of 61 persons (22 pharmacists and 39 dietitians) answered the questionnaire. The item with the highest mean score (standard deviation) for pharmacists was "I feel that I am helpful to patients," at 3.50 (0.74), and for dietitians it was "I have colleagues at my workplace whom I can talk to when I have a problem," at 3.51 (1.00). Conversely, the items with the lowest mean score (standard deviation) were "I am satisfied with my current job" for pharmacists, at $3.14(0.83)$, and "I can grow sufficiently as a professional" for dietitians, at 2.41 (0.97). As a result of factor analysis, the seven-item question could be divided into two factors: "demonstrating expertise" and "overall job satisfaction." The factor-score for "demonstrating expertise" was significantly lower for dietitians than for pharmacists $(p<0.01)$, but there was no significant difference in overall job satisfaction between the two professions $(p=0.36)$. Further research is needed to understand why dietitians find "demonstrating expertise" difficult in pharmacies.

\section{Background}

Japan has one of the fastest rising rates of aging in the world, ${ }^{1)}$ and there is an urgent need to improve community healthcare due to the danger of a decrease in the number of hospital beds in the near future. In response, one of the Japanese government's policies for enhancing community healthcare is to improve the health service functions of community pharmacies. The Ministry of Health, Labour and Welfare (MHLW) has produced its "Pharmacy Vision for Patients" and expects community pharmacies to play a role in providing comprehensive support for patients' health, moving beyond their traditional role of 
simply administering prescribed medicines. ${ }^{2}$ In 2016, the Ministry of Health, Labour and Welfare introduced the "Health Support Pharmacy" program, through which pharmacies that make proactive efforts to support health care are certified as "health support pharmacies." However, as of 2021, five years after the launch of the system, only 2,608 pharmacies have been certified through this program. ${ }^{3)}$ This is only $4.3 \%$ of the total number of pharmacies in Japan (which was 60,171 as of 2019 ), ${ }^{4}$ ) indicating the difficulty of establishing health support services in Japanese pharmacies. Eades et al. has also reported on the difficulties of providing health support in pharmacies, noting that confidence in health support has not improved significantly over the past 10 years and that professional education for pharmacies is needed. ${ }^{5)}$ It has been reported that health promotion in pharmacies can generate a variety of costeffective medical values, although these values vary depending on the disease. ${ }^{6)}$ Therefore, it is desirable for Japanese pharmacies to have such health support capabilities.

Against this backdrop, in Japan, the private sector has begun to take the lead in attempting to retain dietitians in pharmacies. These private companies generally employ dietitians as both dispensing clerks and nutritionists, with the dietitians working as dispensing clerks while performing duties such as nutrition counseling, in-home medical care management guidance, and outreach seminars that are conducted when the pharmacists deem it necessary. This collaboration between pharmacists and dietitians within the pharmacies has great potential for improving health service, such as improving patients' access to nutritional counseling and discovering drug-diet interactions. In fact, there have been reports of cases where obesity has been improved through the guidance of dietitians at pharmacies. ${ }^{7,8)}$ However, it cannot be denied that dietitians at pharmacies are often required to play a role as dispensing clerks, and as a result, they may not be able to provide sufficient nutritional counseling. In fact, it has been reported that $56.1 \%$ of pharmacy dietitians lack confidence in their ability to adequately perform their duties, even though they are aware of the importance of providing nutrition counseling and are more skilled than pharmacists at supporting patients' dietary needs. ${ }^{9}$ ) It has been reported that there is a positive correlation between the level of professionalism of dietitians and job satisfaction. ${ }^{10)}$ Understanding the attitudes of dietitians working in pharmacies is an important issue, since decreased job satisfaction can lead to decreased work attendance ${ }^{11)}$ and retirement, ${ }^{12)}$ and also in a deterioration in health. ${ }^{13)}$

In order to effectively utilize and sustain the pharmacy system in Japan, both pharmacists and dietitians need to maintain a high level of job satisfaction. In order for this to happen, it is necessary for both professions to be able to sufficiently demonstrate their expertise. However, up until now, there has been no questionnaire for measuring these concepts. In this study, we aimed to understand the current level of professionalism and overall job satisfaction of dietitians working in pharmacies, compared to pharmacists.

\section{Methods}

\section{Study Design}


This study was a cross-sectional study using a web-based questionnaire with Google Form (Google LLC). The subjects of this study were pharmacists and dietitians working at pharmacy branches with dietitians in two pharmacy chains. One of the two chain pharmacies has stores throughout Japan, and the other is based in the Kansai region. The recruitment of collaborators was not limited to the region of the stores. In the web questionnaire, the purpose of the study, protection of personal information, and the fact that responses were voluntary were stated on the first page, and responses could be provided only if the respondents agreed to cooperate. The response period was from January to March 2021, and, e-mails were sent to participants once during the response period reminding them to be sure to submit their responses.

\section{Definition of terms}

\section{Job Satisfaction}

There have been many definitions and explanations of job satisfaction in the past. Locke's definition of "a pleasurable or positive emotional state that is related to the work that the individual performs "14) is one of the most important. In this study, we will basically follow this definition in our discussion.

\section{Expertise}

"Expertise" is a word that has many meanings and is in flux. Goldman proposes that:

$S$ is an expert in domain D if and only if S has the capacity to help others (especially laypersons) solve a variety of problems in D or execute an assortment of tasks in $D$ which the latter would not be able to solve or execute on their own. S can provide such help by imparting to the layperson (or other client) his/her distinctive knowledge or skills. ${ }^{15)}$

We think that this interpretation has a high affinity with the medical profession. In this paper, we will use the term "expertise" in accordance with this definition.

\section{Questionnaire}

To measure the attitudes about work of dietitians and pharmacists working in pharmacies, we used a questionnaire that was developed for this study. In developing the questionnaire, we used as our theoretical basis the idea that the most fundamental trend in work values is an increasing orientation toward internal values inherent in the work itself, such as enjoyment working with "colleagues" and the exercise of "professionalism,"16) and reports that job satisfaction in dietitians is related to the degree to which they are able to exercise professionalism. ${ }^{10}$ In this study, professionalism was defined as the degree to which a person can demonstrate expertise, according to Goldman's definition. In the present study, demonstration of expertise refers to work performed by pharmacists that utilizes their pharmacological knowledge, and work performed by dieticians that utilizes their nutritional knowledge. A team of researchers, physicians, and pharmacists with experience in questionnaire development was formed and asked to confirm the validity of the content. In the end, a seven-item questionnaire was 
developed, with questions such as "very much agree," "agree," "can’t say either way," "disagree," and "completely disagree."

\section{Statistical analysis}

For the analysis, we scored the responses to the questionnaire as follows: 5 points for "very much agree," 4 points for "agree," 3 points for "can't say either way," 2 points for "disagree," and 1 point for "completely disagree." The ceiling effect and floor effect were confirmed from the distribution of responses to each item. To confirm the validity of the questionnaire, an exploratory factor analysis was conducted. Kaiser-Meyer-Olkin's sample validity test and Bartlett's sphericity test were used to measure sample validity. The principal factor method was used for factor extraction, and the obtained matrices were rotated using the Oblimin method with Kaiser's normalization. The Kaiser Guttman criterion was used to determine the number of factors. A factor loading of 0.35 was used as the cutoff value. The reliability of the questionnaire was verified by calculating the Cronbach alpha coefficient.

Comparison of scores between pharmacists and dietitians was done by unpaired $t$ test. IBM SPSS Statistics 27 (IBM Tokyo) was used for all analyses.

\section{Results}

A total of 61 persons, 22 pharmacists and 39 dietitians, responded to the survey (response rate: 88.4\%). The mean number of years of service (standard deviation) of the respondents was 6.0 (5.3) years.

\section{Distribution of responses for each question}

Figure 1 shows the distribution of responses by pharmacists and nutritionists, respectively, for each item of the questionnaire. No ceiling or floor effects were found for any of the items. The highest mean score (standard deviation) for the pharmacists was 3.50 (0.74), for "I think I am helpful to patients," and that for the dietitians was 3.51 (1.00), for "I have colleagues at my current workplace whom I can talk to when I have a problem." Conversely, the items with the lowest mean score (standard deviation) were "I am satisfied with my current job" for pharmacists, at $3.14(0.83)$, and "I can grow sufficiently as a professional" for dietitians, at 2.41 (0.97).

\section{Comparison of mean scores for each question between occupations}

Table 1 shows a comparison of the mean scores for each item in the questionnaire. Dietitians scored significantly lower than pharmacists on the following four items: "I am using my expertise in current work," "I feel that I am able to help patients," " I think I am engaged in important work" and "I can grow sufficiently as a professional."

Conceptual Validity and Reliability of the Questionnaire 
Exploratory factor analysis was conducted for the construct validity of the questionnaire, and two factors were obtained, as shown in Table 2. There were no items dropped during the course of the analysis. The Kaiser-Meyer-Olkin sample validity measure was 0.741 , and the significance probability of Bartlett's sphericity test was $<0.001$. The sum of squares of the loadings after factor extraction was 60.128 , the correlation coefficient between factor 1 and factor 2 was 0.450 , and the Cronbach alpha was 0.832 .

Factor 1 was named "demonstration of expertise" because it consisted of questions related to expertise, such as "I am using my expertise in my current work" and "I can grow sufficiently as a professional". Factor 2 was named "overall job satisfaction" because it consisted of questions about overall satisfaction with the respondent's current job, such as "I have colleagues at my current workplace whom I can talk to when I have a problem" and "I want to work at my current workplace for a long time to come."

The mean scores of the questions that constituted each factor were calculated as "factor scores" and compared between pharmacists and dietitians (Table 3). "Demonstrating expertise" scores were significantly lower for dietitians than for pharmacists, but there was no significant difference between the two professions in the score for "overall job satisfaction."

The correlation coefficients of the two factor scores for each occupation were $0.551(p=0.01)$ for pharmacists and $0.482(p=0.01)$ for dietitians, indicating that there was a certain correlation between the two factor scores for both occupations.

\section{Discussion}

In this study, we conducted a cross-sectional survey of the attitudes toward their jobs of pharmacists and dietitians working in pharmacies. The survey questions were designed with reference to an article that the most fundamental trend in work values was an increased orientation toward internal values inherent in the work itself, such as enjoyment with "colleagues" and demonstration of "expertise,"16) and an article that involvement of professionalism is related to job satisfaction. ${ }^{10)}$ The results of factor analysis indicated that the seven items consisted of two factors, "demonstration of expertise" and "overall job satisfaction," and there was a certain correlation between the two factor scores for both occupations. The validity and reliability of this questionnaire were assured to a certain extent. Dietitians scored significantly lower on the factor "demonstration of expertise" than pharmacists, but there was no significant difference in the score of the factor "overall job satisfaction" between the occupations. Although more research is needed to determine why pharmacies are a difficult environment for dietitians to "demonstrate their expertise," we think that the following reasons exist. First, dietitians in pharmacies are currently expected to basically perform as dispensing clerks, so they may not be able to provide nutrition counseling to the extent that they had expected due to their busy schedules. Potential solutions for this are having dietitians learn how to quickly provide nutrition counseling in a limited period of time and increasing the number of employees. In addition, the cooperation of pharmacists and dispensing clerks who are not dietitians may also be necessary. A second possibility is that patients are not aware of the presence of nutritionists in pharmacies due to inadequate publicity. Although there are several ways to publicize the 
presence of a nutritionist in a pharmacy, such as placing a sign or recipes in the store, more active publicity is needed. A third possibility is that there is insufficient education and training for dietitians in pharmacies, both inside and outside of pharmacies. This can be seen in the low score for the question, "I can grow sufficiently as a professional." We believe that providing pharmacy dietitians with specialized opportunities for continuous learning and feedback is essential for improving nutrition counseling in pharmacies. We believe that the authenticity of these factors needs to be investigated in the future, especially through a qualitative approach. In this survey, however, the level of "overall job satisfaction" was the same as that of pharmacists. Further investigation into the reasons for this is needed, but it is possible that external factors such as salary or the management system of the company may affect the level of "job satisfaction." This survey did not investigate these external factors, and further research is needed.

We recognize the following limitations of this survey. First, the sample size is small. Second, the survey did not ask about the status of pharmacists' work or the actual frequency of nutritional counseling, so the interpretation of the "degree" of "demonstration of expertise" was left to the individual respondents. Third, we were not able to examine the factors that affected each factor. Despite the above limitations, we believe that this survey will provide data to examine the perceptions of pharmacists and dietitians in pharmacies with resident dietitians regarding their respective duties.

\section{Declarations}

\section{Acknowledgement}

We would like to thank Michiko Horiguchi for her assistance in conducting the survey, as well as the dietitians and pharmacists in the community pharmacies of the e-pharmacy group, Ito-Yaku Ltd., and the Cocokarafine group Co., Ltd. for their cooperation in this study.

\section{Author's contributions}

MS designed and conducted the study, analyzed the data, and wrote the manuscript. NS provided general research advising. $\mathrm{NI}$ and $\mathrm{KS}$ assisted in conducting the study. MO provided general research advising. All authors read and approved the final manuscript.

\section{Funding}

This study was supported by the Policy-based Medical Services Foundation.

\section{Availability of data and materials}

The supporting data for the findings of this study are available from the corresponding author on request. The data are not publicly available for privacy and ethical reasons.

\section{Ethics approval and consent to participate}


This study was conducted in compliance with the ethical guidelines for "Medical Research Involving Human Subjects." This study was conducted with the approval of the Research Ethics Review Committee of the Osaka University of Pharmaceutical sciences (currently Osaka Medical and Pharmaceutical University) (Approval No.: 0072). Informed consent was obtained from all study participants prior to their participation.

\section{Consent for publication}

Not applicable

\section{Competing interests}

There are no conflicts of interest to declare.

\section{References}

1. Ministry of Health, Labor and Welfare, White Paper on Health, Labor and Welfare https://www.mhlw.go.jp/wp/hakusyo/kousei/16/backdata/01-01-01-05.html. Accessed 19 Oct 2021.

2. Ministry of Health, Labor and Welfare, "Pharmacy Vision for Patients". https://www.mhlw.go.jp/file/04-Houdouhappyou-11121000-lyakushokuhinkyokuSoumuka/vision_1.pdf. Accessed 19 Oct 2021.

3. Ministry of Health, Labor and Welfare, Number of Health Support Pharmacies, https://www.mhlw.go.jp/content/000840397.pdf, Accessed 10 Oct 2021.

4. Ministry of Health, Labor and Welfare, FY 2019 Health Administration Report, https://www.mhlw.go.jp/toukei/saikin/hw/eisei_houkoku/19/dl/kekka5.pdf, Accessedã 8 19 Oct 2021.

5. Eades CE, Ferguson JS, O'Carroll RE. Public health in community pharmacy: a systematic review of pharmacist and consumer views. BMC Public Health. 2011;21;11:582.

6. Steed L, Sohanpal R, Todd A, Madurasinghe VW, Rivas C, Edwards EA, Summerbell CD, Taylor SJ, Walton RT. Community pharmacy interventions for health promotion: effects on professional practice and health outcomes. Cochrane Database Syst Rev. 2019; 6;12(12):CD011207.

7. Koyama Y, Yamauchi K, Sakane N. First report: Obesity improvement using portion control plates by a pharmacy dietitian. Journal of Japan Society for the Study of Obesity, 25Suppl, 293, 2019.

8. Hashizume M, Koyama Y, Yamauchi K, Sakane N. Second report: Obesity improvement using portion control plates by a pharmacy dietitian. Journal of Japan Society for the Study of Obesity, 25Suppl, 294, 2019.

9. Kizaki H, Ota T, Mashima S, Nakamura Y, Kiyokawa S, Kominato H, et al. Questionnaire survey investigation of the present status of dietetic consultation at community pharmacies from the perspectives of registered dietitians and pharmacists. BMC Health Services Research, 21, 935, 2021. 
10. Mortensen JK, Nyland NK, Fullmer S, Eggett DL. Professional involvement is associated with increased job satisfaction among dietitians. J Am Diet Assoc., 2002;102(10):1452-4.

11. Petterson IL, Arnetz BB, Arnetz JE. Predictors of job satisfaction and job influence-results from a national sample of Swedish nurses. Psychother Psychosom, 1995;64:9-19.

12. DeMicco FJ, Olsen MD. The Relationship of work satisfaction and organizational commitment to retirement intention. J Am Diet Assoc, 1988; 89: 1087-91.

13. Faragher EB, Cass M, Cooper CL. The relationship between job satisfaction and health: a metaanalysis. Occup Environ Med. 2005;62(2):105-12.

14. Locke, E.A. (1976) The nature and causes of job satisfaction. In Dunnett, M.D. (Ed.), Handbook of Industrial and Organizational Psychology, 1, 1297-1343. Chicago, IL: Rand McNally.

15. Goldman Al. Expertise. Topoi, 2018; 37: 3-10.

16. Tanabiki Y. Long-Term Trends of Work Values in Japan. The Japanese journal of labour studies, 2017;684:49-58.

\section{Tables}

Due to technical limitations, table 1, 2 and 3 is only available as a download in the Supplemental Files section.

\section{Figures}




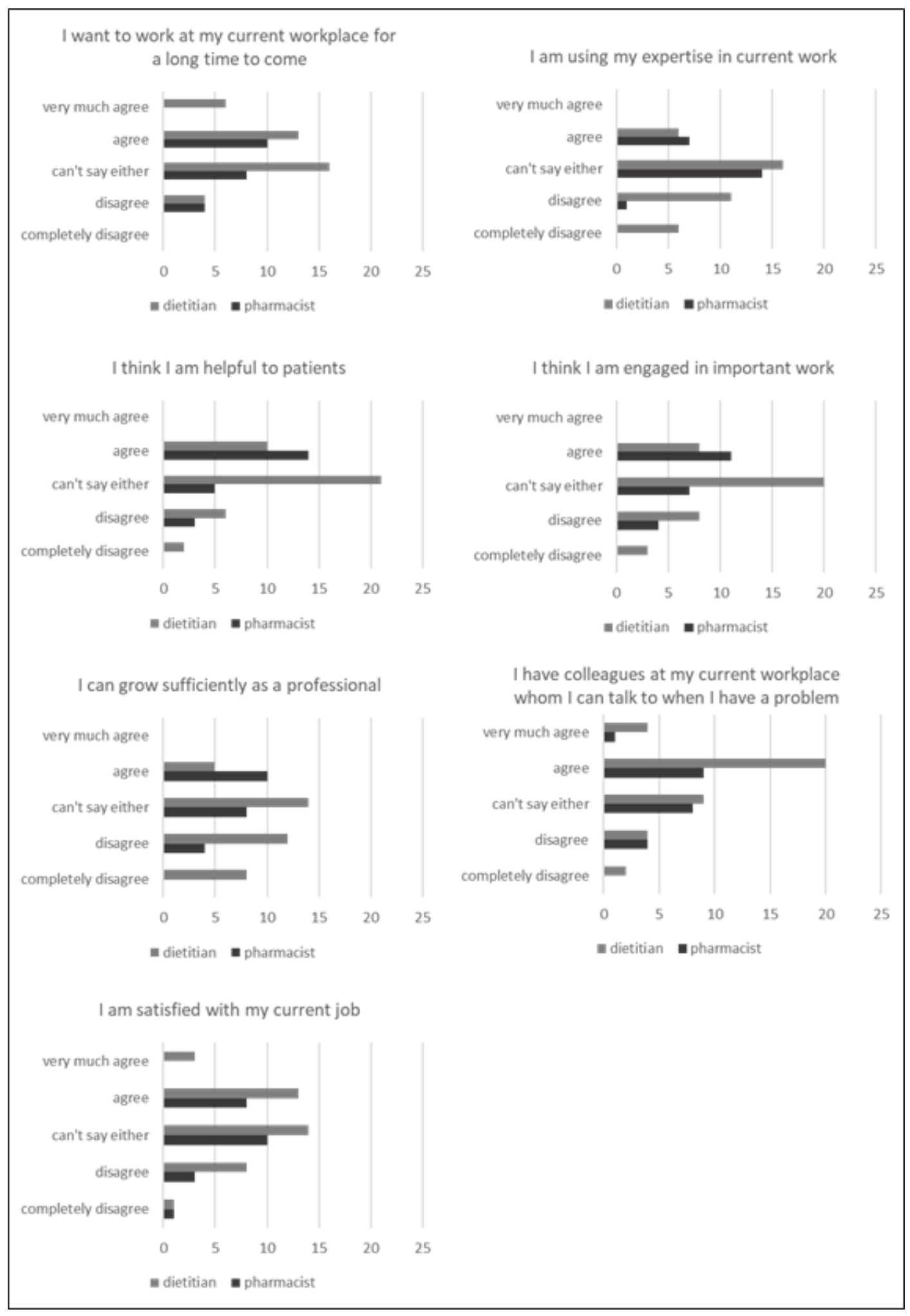

\section{Figure 1}

Figure 1 shows the distribution of responses by pharmacists and nutritionists, respectively, for each item of the questionnaire.

\section{Supplementary Files}


This is a list of supplementary files associated with this preprint. Click to download.

- Tables.xlsx 